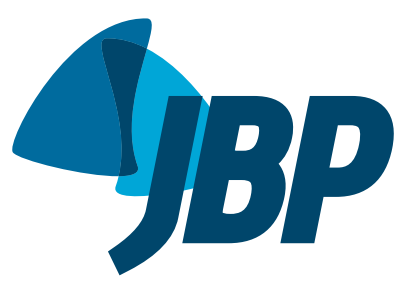

1. Programa de Pós-Graduação em Ciências Cardiovasculares, Universidade Federal Fluminense - UFF - Niterói (RJ) Brasil.

2. Departamento de Medicina Interna, Faculdade de Medicina, Universidade Federal Fluminense - UFF - Niterói (RJ) Brasil.

3. Departamento de Fisiologia e Farmacologia, Universidade Federal Fluminense - UFF - Niterói (RJ) Brasil.

4. Universidade do Estado do Rio de Janeiro - UERJ - Rio de Janeiro (RJ) Brasil.

a. (iD http://orcid.org/0000-0003-4099-1104

b. iD http://orcid.org/0000-0002-1331-723X

c. iD http://orcid.org/0000-0001-7382-3081

d. (iD http://orcid.org/0000-0001-6317-9587

e. iD http://orcid.org/0000-0002-1209-6690

f. (iD http://orcid.org/0000-0002-2284-8251

Submitted: 22 November 2017 Accepted: 26 March 2018

Study carried out at the Hospital Universitário Antonio Pedro, Universidade Federal Fluminense - UFF - Niterói (RJ) Brasil.

\section{Comparison of two smoking cessation interventions for inpatients}

\author{
Antonio Carlos Ferreira Campos ${ }^{1, a}$, Angela Santos Ferreira Nani ${ }^{2, b}$, \\ Vilma Aparecida da Silva Fonseca ${ }^{3, c}$, Eduardo Nani Silva ${ }^{1,2, d}$, \\ Marcos César Santos de Castro ${ }^{2,4, e}$, Wolney de Andrade Martins ${ }^{1,2, f}$
}

\begin{abstract}
Objective: This study aimed to compare the effectiveness of two cognitive behavioral therapy-based smoking cessation interventions initiated during hospitalization and to evaluate the factors related to relapse after discharge. Methods: This was a prospective randomized study involving 90 smokers hospitalized in a university hospital. We collected data related to sociodemographic characteristics, reasons for admission, smokingrelated diseases, smoking history, the degree of nicotine dependence (ND), and the level of craving. Patients were divided into two treatment groups: brief intervention (Brlnter, $n=45$ ); and intensive intervention with presentation of an educational video (InInterV, $n=45)$. To assess relapse, all patients were assessed by telephone interview in the first, third, and sixth months after discharge. Abstinence was confirmed by measurement of exhaled carbon monoxide (eCO). Results: Of the 90 patients evaluated, $55(61.1 \%)$ were male. The mean age was $51.1 \pm 12.2$ years. The degree of ND was elevated in $39(43.4 \%)$, and withdrawal symptoms were present in $53(58.9 \%)$. The mean eCO at baseline was $4.8 \pm 4.5 \mathrm{ppm}$. The eCO correlated positively with the degree of ND $(r=0.244 ; p=0.02)$ and negatively with the number of smoke-free days $(r=-0.284$; $p=0.006)$. There were no differences between the groups in terms of the variables related to socioeconomic status, smoking history, or hospitalization. Of the 81 patients evaluated at 6 months, $33(40.7 \%)$ remained abstinent $(9$ and 24 BrInter and InInterV group patients, respectively; $p=0.001$ ), and 48 (59.3\%) had relapsed (31 and 17 Brlnter and InInterV group patients, respectively; $p=0.001)$. Moderate or intense craving was a significant independent risk factor for relapse, with a relative risk of 4.0 (95\% $\mathbf{C l}$ : 1.5 10.7; $p<0.00001)$. Conclusions: The inclusion of an educational video proved effective in reducing relapse rates. Craving is a significant risk factor for relapse.
\end{abstract}

Keywords: Smoking cessation; Tobacco use disorder; Inpatients; Hospitalization.

\section{INTRODUCTION}

Tobacco-related diseases constitute one of the main causes of hospital admission. ${ }^{(1-3)}$ When smoking patients are hospitalized, it is recommended that they be given counseling and treatment for nicotine dependence, during hospitalization and for at least four weeks after discharge. ${ }^{(4)}$ However, very few hospitals treat nicotine-dependent patients during hospitalization. Due to smoking restrictions on hospital premises, such patients feel forced to quit smoking regardless of their level of motivation to do so. Therefore, hospitalization provides a unique opportunity to approach those patients who wish to quit smoking. ${ }^{(5)}$ Various studies ${ }^{(3,6-8)}$ have shown that, despite the fact that smoking is not allowed in hospitals, $25 \%$ of nicotine-dependent patients smoke during hospitalization; $55 \%$ of smoking patients report withdrawal symptoms during hospitalization; only $6 \%$ of such patients receive nicotine replacement therapy (NRT); and $63 \%$ of patients receiving NRT relapse during the first week after hospital discharge (45\% relapsing on the first day).
Data suggest that $50 \%$ of smokers stop smoking without assistance immediately after a cardiovascular event that results in hospitalization. However, the smoking relapse rate after hospitalization for a cardiovascular event is $50 \%$. The occurrence of withdrawal symptoms immediately after discharge and of depressive symptoms 3-6 months later are the main factors related to smoking relapse after hospitalization.

Many types of resources are used for outpatient smoking cessation treatment, including self-help materials, counseling, cognitive behavioral therapy, and pharmacological treatment. ${ }^{(9)}$ Nevertheless, there are few data available about intra-hospital smoking cessation therapy. According to a recent meta-analysis, ${ }^{(10)}$ smoking cessation intervention during hospitalization must be intensive to be effective. The objective of this study was to compare two cognitive behavioral therapy-based interventions for smoking cessation in hospitalized patients, in terms of their effectiveness, and to evaluate the factors associated with relapse after discharge. A secondary objective was to evaluate the effectiveness of a video 
counseling intervention, which was tested because it is feasible, requiring fewer resources, and if effective would be a useful tool at every kind of hospital, even when specialists are not available.

\section{METHODS}

This was a randomized prospective study involving smokers hospitalized between January and December of 2016 on the medical or surgical ward of Antônio Pedro University Hospital, a 232-bed teaching community hospital located in the city of Niterói, Brazil. For the purposes of this study, we excluded a total of 108 of those beds in the departments of obstetrics, neonatal care, and pediatrics, as well as in the nursery, adult ICU, and emergency room.

To be eligible for the study, subjects had to be current cigarette smokers; between 18 and 80 years of age; and motivated to remain abstinent from smoking after hospital discharge. Individuals who had smoked regularly (at least one cigarette per day) for at least 30 days before hospitalization, were classified as current smokers. ${ }^{(11)}$ Prospective subjects were excluded if they were receiving end-of-life care, were clinically unstable, had cognitive or memory deficits, had a psychiatric disorder, or were pregnant.

Patients were enrolled within the first $48 \mathrm{~h}$ after hospital admission, at which time an interviewer collected data related to sociodemographic characteristics, medical history, smoking history, intention to stop smoking during hospitalization/after discharge, and nicotine withdrawal symptoms. The level of nicotine dependence was assessed with the Fagerström Test for Nicotine Dependence (FTND). ${ }^{(12)}$ To assess the level of nicotine craving, we used the Brief Questionnaire of Smoking Urges (QSU-brief), (13) whereas we assessed the use/ abuse of alcohol with the Cut down, Annoyed, Guilty, and Eye-opener questionnaire. ${ }^{(14)}$ Patient records were further evaluated in order to confirm and complement the data.

\section{Interventions}

We calculated that a sample of 90 subjects would be required in order to achieve sufficient statistical power to identify differences between two groups. Therefore, 90 inpatients were randomly assigned to one of two treatment groups: the brief intervention (BrInter) group $(n=45)$ and the intensive intervention with an educational video (InInterV) group $(n=45)$.

\section{BrInter group}

Patients in the BrInter group received counseling on the dangers of smoking and the benefits of quitting in an ordinary session lasting $10 \mathrm{~min}$. No audiovisual resources were used, nor was any pharmacological intervention proposed.

\section{InInterV group}

The intensive cognitive behavioral therapy-based intervention was performed by a researcher who had previously been trained in smoking cessation treatment at the Brazilian National Cancer Institute. Patients assigned to the InInterV group were counseled in a session that lasted approximately $40 \mathrm{~min}$, comprising a 10-min oral intervention and a 30-min educational video presentation. In that session, the counselor reviewed the dangers of smoking and the benefits of quitting; assessed the knowledge and beliefs of the participant, as well as the potential barriers to smoking cessation; explained the mechanisms of nicotine dependence and the symptoms of withdrawal; presented counter-arguments to belief barriers; and discussed behavioral self-management strategies to counter relapse triggers. No pharmacological intervention was proposed. A team of researchers, composed of a cardiologist, a pulmonologist, and a psychiatrist created the intellectual content and produced the video. The video presentation was performed with a notebook computer installed at the bedside. This video will be made available upon request.

\section{Follow up}

All participants were contacted by telephone at 1 , 3 , and 6 months after discharge from the hospital. During hospitalization and at 6 months after discharge, smoking status was assessed and self-reported abstinence was biochemically validated by measuring exhaled carbon monoxide (eCO) with a portable breath analyzer (Micro CO; Micro Medical Ltd, Rochester, UK). Values of eCO over 6 ppm were considered indicative of recent smoking. ${ }^{(15)}$

In the telephone interviews conducted at 6 months after discharge, additional data were obtained. Patients were asked about possible improvements in their lives after smoking cessation, such as those related to respiratory symptoms, family relationships, physical activities, and financial well-being. They were also invited to schedule an appointment at our hospital within the next seven days, in order to submit to eCO evaluation.

For patients who were unable to come to the hospital, the eCO measurement was performed in the home. Patients who could not be contacted after at least two telephone calls were considered lost to follow-up. Participants who had relapsed were encouraged to undergo outpatient treatment at our institution.

\section{Statistical analysis}

The sample size $(n=90)$ was calculated according to the expected prevalence of smoking among hospitalized patients. That calculation was based on data collected in a previous study conducted by our group, in which that prevalence was found to be $13 \%$. $^{(16)}$

Continuous variables are expressed as mean and standard deviation or as median where appropriate. Categorical variables are expressed as absolute and relative frequencies. To compare the two groups, the Mann-Whitney $U$ test was used for continuous variables, whereas the chi-square test and Fisher's exact test were used for categorical variables. Logistic 
regression analysis was used in order to identify independent predictors of relapse. The Kaplan-Meier method and log-rank tests were used in order to identify event-free patients. An event was defined as any relapse after the initial intervention. The strength of the associations between continuous variables was determined with Spearman's correlation coefficient. To evaluate the distribution of the data collected, we used the Kolmogorov-Smirnov test. For variables that did not present a normal distribution, due to dispersion, we used nonparametric methods of analysis. A level of significance of $5 \%$ was adopted. All statistical analyses were performed with the Statistical Analysis System, version 6.11 (SAS Institute Inc., Cary, NC, USA) and the IBM SPSS Statistics software package, version 18.0 (IBM Corporation, Armonk, NY, USA).

The study was approved by the Research Ethics Committee of Fluminense Federal University School of Medicine (Reference no. 0008.0.258.000-10). All participating patients gave written informed consent.

\section{RESULTS}

Of the 90 hospitalized smokers evaluated, 55 $(61.1 \%)$ were male; 47 (52.2\%) were unmarried; only $30(32.3 \%)$ had graduated high school; $65(72.2 \%)$ earned less than minimum wage; 47 (52.2\%) were hospitalized on medical wards; and 43 (47.8\%) were hospitalized on surgical wards. The mean age of the patients was $51 \pm 12.2$ years (range, 20-72 years). The reasons for admission were as follows: cancer (in $23.3 \%$ ); cardiovascular diseases (in $21.1 \%$ ), primarily coronary artery disease; respiratory diseases (in $14.4 \%$ ); and osteoarticular diseases (in 13.4\%). There were no significant differences between the groups in terms of the reasons for admission.

The most prevalent smoking-related diseases prior to the hospitalization were hypertension (in 51.1\%), gastritis (in $33.3 \%$ ), COPD (in $28.8 \%$ ), and diabetes mellitus (in 26.6\%). Of the 35 female smokers, 14 $(40 \%)$ reported having had at least one miscarriage. Of the 90 patients evaluated, $16(17.8 \%)$ reported dependence on alcohol and $19(21.1 \%)$ reported dependence on one or more other drugs. Seventy-eight $(86.7 \%)$ reported having a sedentary lifestyle.

Among the patients evaluated, the mean number of cigarettes smoked daily was $20.7 \pm 13.1$, the mean time since taking up the smoking habit was $34.8 \pm$ 13.5 years, the mean smoking history was $38.8 \pm 31.4$ pack-years, and the mean age at smoking initiation was $15.9 \pm 5.4$ years. In addition, the degree of nicotine dependence was classified as high or very high in 40 $(43.4 \%)$ of the patients and $58(64.5 \%)$ had already attempted to quit smoking at least once. Patients gave the following reasons for remaining abstinent after hospital discharge: health concerns (in 85 patients); family related concerns (in 13); financial problems (in 8); aesthetic concerns (in 3); improvement in their quality of life (in 2); social acceptance (in 2); improved personal hygiene (in 2); and religious concerns (in 1).
All patients reported needing help to remain abstinent. During hospitalization, 53 (58.9\%) of the 90 patients reported at least one nicotine-withdrawal symptom and presented at least a minimum or a light degree of craving according to the QSU-brief. The mean eCO in the initial evaluation was $4.8 \pm 4.5 \mathrm{ppm}$, which correlated positively with the FTND score $(r=0.244$; $p=0.020)$ and negatively with smoke-free days at enrollment $(r=-0.284 ; p=0.006)$.

Of the 90 patients evaluated, 9 were excluded from the 6-month assessment: due to death, in 5 (3 BrInter group patients and 2 InInterV group patients); and due to loss to follow-up, in 4 (2 BrInter group patients and 2 InInterV group patients). Therefore, a total of 81 patients were evaluated at 6 months after discharge. No significant difference was observed between the two groups in terms of demographic characteristics, socioeconomic variables, or smoking history (Tables 1 and 2).

At 6 months of follow-up, the estimated overall abstinence rate was $40.7 \%, 9$ and 24 patients in the BrInter and InInterV groups, respectively, having remained abstinent from smoking, whereas the estimated overall relapse rate was 59.3\%, 31 and 17 patients in the BrInter and InInterV groups, respectively, having relapsed. The mean eCO at 6 months was 0.7 $\pm 0.6 \mathrm{ppm}$ (range, 0-2 ppm). As can be seen in Figure 1 , there were fewer cases of relapse in the InInterV group than in the BrInter group.

Of the 48 patients who relapsed, 38 (79.1\%) had resumed smoking within the first month after discharge -27 within the first week (15 on the first day); $8(16.6 \%)$ had resumed smoking between the first and third month; and $2(4.1 \%)$ had resumed smoking between the fourth and sixth month. As shown in Figure 2, there was a significant difference between the BrInter and InInterV groups in terms of the event-free curve ( $p=0.002)$, the InInterV group presenting a higher event-free rate. The mean time to relapse was approximately 24 days. The main reason for relapse, reported by 37 patients $(77.0 \%)$, was craving.

In the comparison between the patients who had relapsed by 6 months after discharge and those who had not (Figure 3), the former presented significantly higher QSU-brief scores ( $p=0.001)$. The differences between the relapsing and abstinent patients were not significant for any of the other variables evaluated: the condition that prompted admission ( $p=0.75$ ); alcohol dependence $(p=0.31)$; drug dependence ( $p$ $=0.47)$; and a sedentary lifestyle $(p=0.59)$.

There was a significant positive correlation between the FTND score and the QSU-brief score $(r=0.209$; $p=0.048$ ), whereas there was a significant negative correlation between the number of smoke-free days and the QSU-brief score $(r=-0.353 ; p=0.001)$. Figure 4 shows the ROC curve for the QSU-brief scores vis-à-vis relapse. The best QSU-brief cut-off score for identifying relapse was 20 , which had a sensitivity of $66.7 \%$ and a specificity of $72.7 \%$. According to the 
Table 1. Demographic and socioeconomic characteristics of the patients evaluated, by treatment group.

\begin{tabular}{|c|c|c|c|c|}
\hline \multicolumn{2}{|c|}{ Variables } & \multicolumn{2}{|c|}{ Group } & \multirow[t]{2}{*}{ p* } \\
\hline & & $\begin{array}{c}\text { Brinter } \\
(n=45) \\
n(\%)\end{array}$ & $\begin{array}{c}\text { InlnterV } \\
(n=45) \\
n(\%)\end{array}$ & \\
\hline \multirow{2}{*}{ Gender } & Male & $28(62.2)$ & $27(60.0)$ & \multirow{2}{*}{0.83} \\
\hline & Female & $17(37.8)$ & $18(40.0)$ & \\
\hline Age (years) & Median & 54 & 54 & 0.47 \\
\hline \multirow{2}{*}{ Marital status } & Married & 22 (48.9) & $21(46.7)$ & \multirow{2}{*}{0.83} \\
\hline & Unmarried & $23(51.1)$ & $24(53.3)$ & \\
\hline \multirow{3}{*}{ Religion } & Catholic & 31 (68.9) & $28(62.2)$ & \multirow{3}{*}{0.51} \\
\hline & Other & $14(31.1)$ & 17 (37.8) & \\
\hline & $<9$ years & $20(44.4)$ & $20(44.4)$ & \\
\hline \multirow[t]{2}{*}{ Schooling } & $9-11$ years & $14(31.1)$ & $7(15.6)$ & \multirow[t]{2}{*}{0.13} \\
\hline & $\geq 12$ years & $11(24.4)$ & $18(40.0)$ & \\
\hline Income & (US\$/year) & 4,300 & 4,300 & 0.16 \\
\hline
\end{tabular}

BrInter: brief intervention; and InInterV: intensive intervention with an educational video. *Mann-Whitney test.

Table 2. Smoking variables among the patients evaluated, by treatment group. ${ }^{\mathrm{a}}$

\begin{tabular}{|c|c|c|c|}
\hline \multirow[t]{2}{*}{ Variables } & \multicolumn{2}{|c|}{ Group } & \multirow[t]{2}{*}{ p* } \\
\hline & $\begin{array}{c}\text { Brlnter } \\
(n=45)\end{array}$ & $\begin{array}{l}\text { InlnterV } \\
(n=45)\end{array}$ & \\
\hline Age at smoking initiation (years) & $16.0 \pm 5.5$ & $15.8 \pm 5.4$ & 0.73 \\
\hline Time since smoking initiation (years) & $33.7 \pm 13.8$ & $35.9 \pm 13.3$ & 0.48 \\
\hline Cigarettes smoked/day & $21.2 \pm 12.1$ & $20.2 \pm 14.2$ & 0.61 \\
\hline Smoking history (pack-years) & 30 & 34 & 0.99 \\
\hline Smoking cessation attempts & 1 & 1 & 0.98 \\
\hline FTND score & $5.2 \pm 2.0$ & $5.1 \pm 2.6$ & 0.91 \\
\hline Initial eCO (ppm) & $5.4 \pm 5.4$ & $4.3 \pm 3.4$ & 0.65 \\
\hline
\end{tabular}

BrInter: brief intervention; InInterV: intensive intervention with an educational video; FTND: Fagerström Test for Nicotine Dependence; and eCO: exhaled carbon monoxide. a Values expressed as mean \pm SD or median. *MannWhitney test.

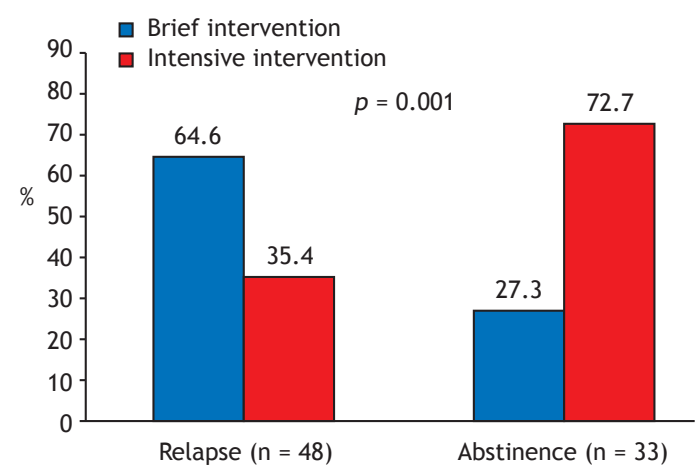

Figure 1. Comparison between the groups studied, in terms of the rates of relapse and abstinence, at 6 months after discharge from the hospital.

logistic regression, the factors that were independent predictors of relapse were being in the BrInter group ( $p$ $=0.008)$ and having moderate or intense cravings $(p=$ 0.034 ), with relative risks of 3.9 and 3.0 , respectively.

Of the 33 patients who had remained abstinent throughout the 6-month follow-up period, 18 (54.5\%) reported improvement in their respiratory symptoms; $15(45.4 \%)$ reported improvement in their financial situation; $13(39.3 \%)$ reported improvement in their

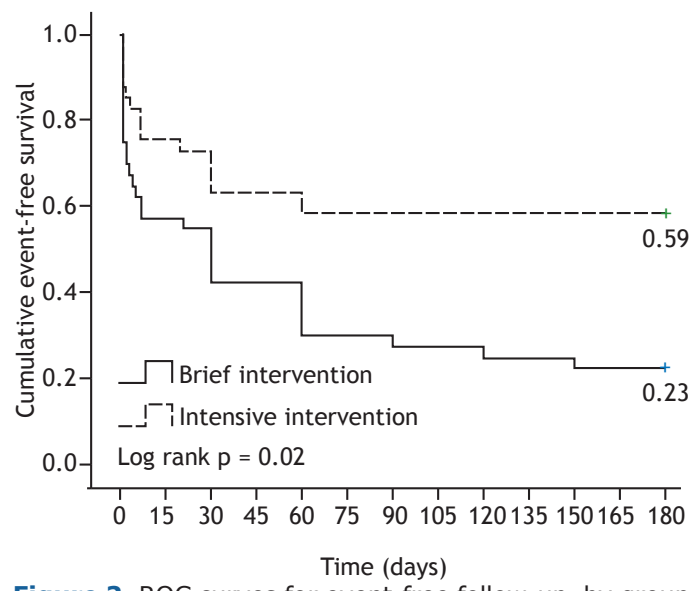

Figure 2. ROC curves for event-free follow-up, by group.

sense of smell; and $10(30.3 \%)$ reported improvement in their sense of taste. Only one patient reported having observed no improvement whatsoever.

\section{DISCUSSION}

Every year, millions of smokers are hospitalized for smoking-related diseases. Those admissions constitute a window of opportunity for implementing smoking 
cessation programs. ${ }^{(7)}$ Smokers who are hospitalized are more susceptible to anti-smoking messages for a number of reasons ${ }^{(17)}$ : their frailty; their fear of complications or death from the disease that prompted their admission; and the fact that they are forced to refrain from smoking because of the smoking ban in hospitals. Few hospitals identify smokers during hospitalization, and even fewer offer smoking cessation treatment and follow-up after discharge. ${ }^{(5)}$ In this study, all hospitalized smokers reported being motivated to quit smoking for good, although they stated that they needed help to remain abstinent, supporting the concept that hospitalization is an opportune time to initiate smoking cessation treatment.

There have been few epidemiological studies on in-hospital smoking cessation treatment and its management. In a previous study conducted by our group and involving 136 hospitalized patients, ${ }^{(16)}$ $18(13.2 \%)$ of the patients were smokers. Of those 18 patients, 16 (88.9\%) experienced withdrawal symptoms during hospitalization. In the present study, the prevalence of smoking was lower (8.1\%) and only $53(58.9 \%)$ of the 90 patients experienced

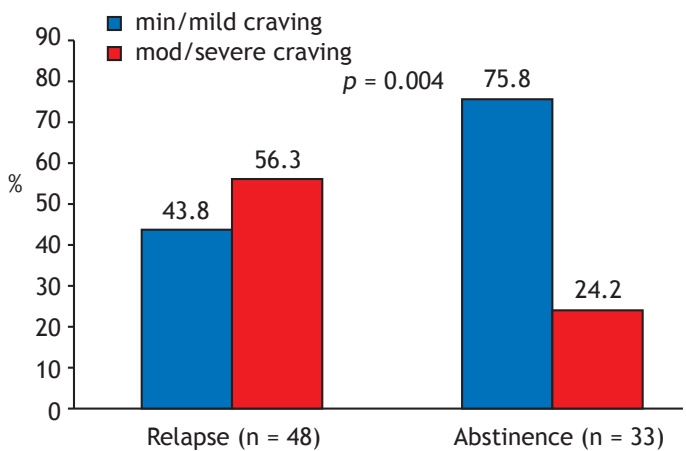

Figure 3. Scores on the Brief Questionnaire of Smoking Urges, by outcome.

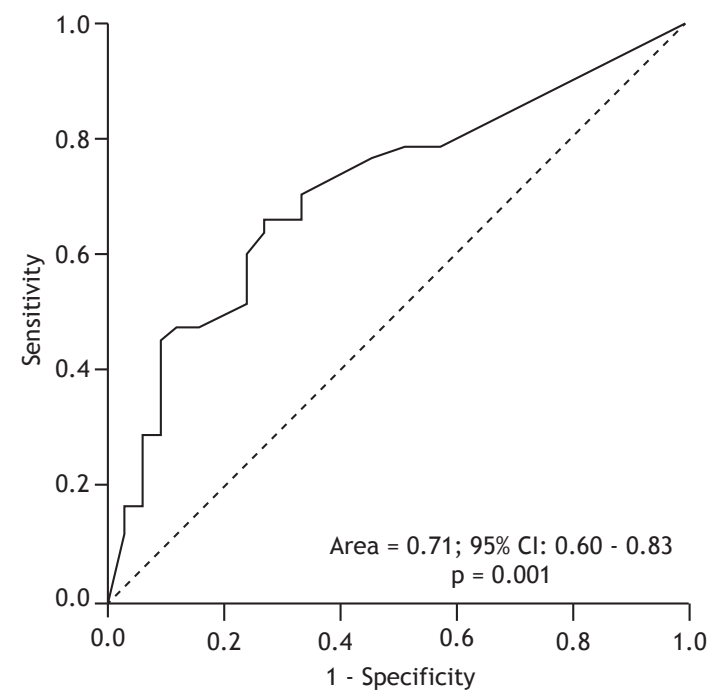

Figure 4. ROC curve for the Brief Questionnaire of Smoking Urges score, in relation to relapse. withdrawal symptoms, minimum or mild craving being the predominant symptom. Warner et al.(18) did not observe intense withdrawal symptoms in smokers hospitalized for elective surgery. The authors suggest that psychological stress caused by the surgical procedure reduced withdrawal symptoms. A study conducted in a hospital in the United States evaluated 650 hospitalized smokers and found a prevalence of $25 \%$ of current smoking among inpatients, $55 \%$ of the smokers reporting withdrawal symptoms during their hospital stay. ${ }^{(19)}$ In smoke-free psychiatric hospitals, nearly $50 \%$ of hospitalized patients are smokers. ${ }^{(20)}$ Emmons \& Goldstein ${ }^{(5)}$ found the prevalence of smoking to be $16 \%$ among 304 patients admitted to a cardiovascular disease ward. The reported prevalence of smoking at various hospitals ranges from $12.1 \%$ to $34.0 \%$. $^{(21-23)}$

Smoking cessation treatment programs for hospitalized patients have been implemented worldwide, ${ }^{(24,25)}$ with significant variation in the rates of success. Studies of different intervention techniques for smoking cessation among hospitalized patients have produced inconsistent, unreliable results. ${ }^{(25,26)}$ In a review of several interventional studies of smoking among hospitalized patients, ${ }^{(17)}$ patient follow-up at 30 days after hospital discharge was found to significantly reduce the relapse rate over the subsequent 6 months. This indicates the strategic need to monitor patients after hospital discharge. Hajek et al. (27) evaluated 540 smokers hospitalized after myocardial infarction or for coronary artery bypass surgery and concluded that a brief intervention during hospitalization was insufficient to prevent relapse. Simon et al. ${ }^{(7)}$ demonstrated that intensive medical advice during hospitalization, together with use of NRT for 2 months and telephone support after hospital discharge, increased smoking cessation in comparison with minimum in-hospital counseling. Wolfenden et al. ${ }^{(28)}$ showed that hospital intervention longer than $20 \mathrm{~min}$, followed by at least five telephone calls after discharge, for a minimum of 3 months, is effective to increase smoking cessation rates. In two systematic reviews of studies of smoking cessation interventions in hospitalized patients-published in 2003 and 2007, involving 17 and 33 trials, respectively $(29,30)$ - the authors concluded that intensive behavioral interventions that begin during a hospital stay and extend for at least 30 days after discharge increase smoking cessation rates. Such interventions are effective regardless of the diagnosis at admission. Brief interventions have not been shown to provide significant benefits from a statistical point of view. Similar results were obtained in smokers admitted to the hospital because of cardiovascular disease. In that subgroup, intensive intervention with support after discharge increased the smoking cessation rate, no such increase being observed after a brief intervention. ${ }^{(19)}$ An updated review, involving 50 trials and published in 2012, ${ }^{(10)}$ confirmed those findings and showed that smoking cessation rates were significantly higher after intensive counseling plus NRT than after 
counseling alone, although there is insufficient evidence to conclude that adding bupropion or varenicline to intensive counseling results in cessation rates that are higher than those achieved with counseling alone. In the present study, the use of an intensive approach with an educational video presentation followed by telephone contact was found to be superior to the brief intervention regarding the relapse rate at 6 months of follow-up.

Relapse is a common event among former smokers. Seventy-five percent of abstinent individuals relapse within the first 12 months, most relapsing within the first 6 months, regardless of the nature of the initial intervention. ${ }^{(31,32)}$ In our study, $48(59.3 \%)$ of the 81 smokers evaluated at 6 months after discharge had relapsed. Of those 48 patients, 38 (79.1\%) resumed smoking within the first month after hospital discharge, the relapse rate progressively decreasing over time, similar to what has been reported in other trials. ${ }^{(32,33)}$ Hawkins et al. ${ }^{(33)}$ showed that the relapse rate decreases in direct proportion to the duration of abstinence, as was also shown by Hughes et al. ${ }^{(34)}$ in a meta-analysis of smoking relapse after 12 months of abstinence. These data demonstrate the need for greater support during the first months of smoking abstinence. Goodman et al. ${ }^{(35)}$ reviewed the history of smoking cessation during hospitalization in a smoke-free hospital and showed that only $7 \%$ of patients remained abstinent from smoking at 6 months after discharge. Among the patients who relapsed in that study, 45\% did so on the first day after discharge.

The potential predictors of smoking relapse vary among treatment centers. In the present study, only the degree of craving was found to be an independent predictor of relapse, which differs from the findings of previous studies. ${ }^{(33,36-38)}$

Knowledge of long-term abstinence rates after hospital discharge is extremely important for evaluating the effectiveness of inpatient treatments. In the present study, the abstinence rate among the patients evaluated at 6 months after discharge was $40.7 \%$, higher than that reported in the literature. ${ }^{(31-33)}$

Here, we have presented a cognitive behavioral therapy-based technique that is easily accessible and inexpensive. This intervention, which can be applied by doctors and other health professionals, proved to be effective in reducing long-term relapse rates. Because craving at admission was the main predictor of relapse, the technique could be complemented with medication (NRT, bupropion, or varenicline) or treatment for the comorbid psychiatric disorders emerging with abstinence, on an individual and selective basis.

\section{REFERENCES}

1. Ockene IS, Miller NH. Cigarette smoking, cardiovascular disease and stroke: a statement for healthcare professionals from the American Heart Association. American Heart Association Task Force on Risk Reduction. Circulation. 1997;96(9):3243-7. https://doi org/10.1161/01.CIR.96.9.3243

2. Juster HR, Loomis BR, Hinman TM, Farrelly MC, Hyland A, Bauer UE, et al. Declines in hospital admissions for acute myocardial infarction in New York state after implementation of a comprehensive smoking ban. Am J Public Health. 2007;97(11):2035-9. https://doi.org/10.2105/ AJPH.2006.099994

3. Mohiuddin SM, Moos AN, Hunter CB, Grollmes TL, Cloutier DA Hilleman DE. Intensive smoking cessation intervention reduces mortality in high-risk smokers with cardiovascular disease. Chest. 2007;131(2):446-52. https://doi.org/10.1378/chest.06-1587

4. Reichert J, Araújo AJ, Gonçalves CM, Godoy I, Chatkin JM, Sales MP, et al. Smoking cessation guidelines-2008. J Bras Pneumol. 2008;34(10):845-80. https://doi.org/10.1590/S180637132008001000014

5. Emmons KM, Goldstein MG. Smokers who are hospitalized: a window of opportunity for cessation interventions. Prev Med. 1992;21(2):262-9. https://doi.org/10.1016/0091-7435(92)90024-C

6. Molyneux A, Lewis S, Leivers U, Anderton A, Antoniak M, Brackenridge $A$, et al. Clinical trial comparing nicotine replacement therapy (NRT) plus brief counselling, brief counselling alone, and minimal intervention on smoking cessation in hospital inpatients. Thorax. 2003;58(6):484-8. https://doi.org/10.1136/thorax.58.6.484

7. Simon JA, Carmody TP, Hudes ES, Snyder E, Murray J. Intensive smoking cessation counseling versus minimal counseling among hospitalized smokers treated with transdermal nicotine replacement: a randomized trial. Am J Med. 2003;114(7):555-62. https://doi. org/10.1016/S0002-9343(03)00081-0

8. Rigotti NA, Arnsten JH, McKool KM, Wood-Reid KM, Singe $\mathrm{DE}$, Pasternak RC. The use of nicotine-replacement therapy by hospitalized smokers. Am J Prev Med. 1999;17(4):255-9. https://doi org/10.1016/S0749-3797(99)00095-1

9. Le Foll B, George TP. Treatment of tobacco dependence: integrating recent progress into practice. CMAJ. 2007;177(11):1373-80. https:// doi.org/10.1503/cmaj.070627

10. Rigotti NA, Clair C, Munafò MR, Stead LF. Interventions for smoking

cessation in hospitalized patients. Cochrane Database Syst Rev. 2012;(5):CD001837. https://doi.org/ 10.1002/14651858.CD001837. pub2

11. Stramari LM, Kurtz M, Silva LC. Prevalence of and variables related to smoking among medical students at a university in the city of Passo Fundo, Brazil. J Bras Pneumol. 2009;35(5):442-8. https://doi. org/10.1590/S1806-37132009000500009

12. Fagerstrom KO, Schneider NG. Measuring nicotine dependence: a review of the Fagerstrom Tolerance Questionnaire. J Behav Med. 1989;12(2):159-82. https://doi.org/10.1007/BF00846549

13. Araujo RB, Oliveira MS, Moraes JF, Pedroso RS, Port F, De Castro MG. Validation of the Brazilian version of Questionnaire of Smoking Urges-Brief. Rev Psiq Clin. 2007;34(4):166-75. https://doi. org/10.1590/S0101-60832007000400002

14. Mayfield D, McLeod G, Hall P. The CAGE questionnaire: validation of a new alcoholism screening instrument. Am J Psychiatry. 1974;131(10):1121-3

15. Stelmach R, Fernandes FL, Carvalho-Pinto RM, Athanazio RA Rached SZ, Prado GF, et al. Comparison between objective measures of smoking and self-reported smoking status in patients with asthma or COPD: are our patients telling us the truth? J Bras Pneumol. 2015;(2):124-32. https://doi.org/10.1590/S180637132015000004526

16. Ferreira ÂS, Campos AC, dos Santos IP, Beserra MR, Silva EN Fonseca VA. Smoking among inpatients at a university hospital. J Bras Pneumol. 2011;37(4):488-94. https://doi.org/10.1590/S180637132011000400011

17. Munafò M, Rigotti N, Lancaster T, Stead L, Murphy M. Interventions for smoking cessation in hospitalized patients: a systematic review. Thorax. 2001;56(8):656-63. https://doi.org/10.1136/thorax.56.8.656

18. Warner DO, Patten CA, Ames SC, Offord K, Schroeder D. Smoking behavior and perceived stress in cigarette smokers undergoing elective surgery. Anesthesiology. 2004;100(5):1125-37. https://doi. org/10.1097/00000542-200405000-00014

19. Rigotti NA, Arnsten JH, McKool KM, Wood-Reid KM, Pasternak RC Singer DE. Smoking by patients in a smoke-free hospital: prevalence, predictors, and implications. Prev Med. 2000;31(2 Pt 1):159-66. https://doi.org/10.1006/pmed.2000.0695 
20. Prochaska JJ, Gill P, Hall SM. Treatment of tobacco use in an inpatient psychiatric setting. Psychiatr Serv. 2004;55(11):1265-70. https://doi.org/10.1176/appi.ps.55.11.1265

21. Oliveira MV, Oliveira TR, Pereira CA, Bonfim AV, Leitão Filho FS, Voss LR. Smoking among hospitalized patients in a general hospital. J Bras Pneumol. 2008;34(11):936-41. https://doi.org/10.1590/S180637132008001100008

22. Tanni SE, Iritsu NI, Tani M, Camargo PA, Sampaio MG, Godoy I, et al. Evaluation of hospitalized patients in terms of their knowledge related to smoking. J Bras Pneumol. 2010;36(2):218-23. https://doi. org/10.1590/S1806-37132010000200010

23. Bösch D. Smoking habits and teachable moment among hospitalized patients admitted to the internal medicine department. Chest Dis Rep. 2012;2(1):e6. https://doi.org/10.4081/cdr.2012.e6

24. Bolliger CT, van Biljon X, Humair JP, El Fehri V, Cornuz J. Promoting hospital-based smoking cessation services at major Swiss hospitals: a before and after study. Swiss Med Wkly. 2008;138(29-30):427-31.

25. Borglykke A, Pisinger $C$, Jørgensen $T$, Ibsen $H$. The effectiveness of smoking cessation groups offered to hospitalised patients with symptoms of exacerbations of chronic obstructive pulmonary disease (COPD). Clin Respir J. 2008;2(3):158-65. https://doi. org/10.1111/j.1752-699X.2008.00055.x

26. Hjalmarson A, Boëthius G. The effectiveness of brief advice and extended smoking cessation counseling programs when implemented routinely in hospitals. Prev Med. 2007;45(2-3):202-7. https://doi.org/10.1016/j.ypmed.2007.06.014

27. Hajek P, Taylor TZ, Mills P. Brief intervention during hospital admission to help patients to give up smoking after myocardial infarction and bypass surgery: randomized controlled trial. BMJ. 2002;324(7329):87-9. https://doi.org/10.1136/bmj.324.7329.87

28. Wolfenden L, Campbell E, Walsh R, Wiggers J. Smoking cessation interventions for in-patients: a selective review with recommendations for hospital-based health professionals. Drug Alcohol Rev. 2003;22(4):437-52. https://doi.org/10.1080/095952303 10001613967
29. Rigotti NA, Munafo MR, Murphy MF, Stead LF. Interventions for smoking cessation in hospitalized patients. Cochrane Database Syst Rev. 2003;(1):CD001837

30. Rigotti NA, Munafo MR, Stead LF. Interventions for smoking cessation in hospitalized patients. Cochrane Database Syst Rev. 2007;(3):CD001837. https://doi.org/10.1002/14651858.CD001837. pub2

31. Agboola S, McNeill A, Coleman T, Leonardi Bee J. A systematic review of the effectiveness of smoking relapse prevention interventions for abstinent smokers. Addiction. 2010;105(8):1362-80. https://doi.org/10.1111/j.1360-0443.2010.02996.x

32. Ferguson J, Bauld L, Chesterman J, Judge K. The English smoking treatment services: one-year outcomes. Addiction. 2005;100Supp 2:59-69. https://doi.org/10.1111/j.1360-0443.2005.01028.x

33. Hawkins J, Hollingworth W, Campbell R. Long-term smoking relapse: a study using the British house hold panel survey. Nicotine Tob Res. 2010;12(12):1228-35. https://doi.org/10.1093/ntr/ntq175

34. Hughes JR, Peters EN, Naud S. Relapse to smoking after 1 year of abstinence: a meta-analysis. Addict Behav. 2008;33(12):1516-20. https://doi.org/10.1016/j.addbeh.2008.05.012

35. Goodman MJ, Nadkarni M, Schorling JB. The Natural History of Smoking Cessation Among Medical Patients in a SmokeFree Hospital. Subst Abus. 1998;19(2):71-79. https://doi. org/10.1080/08897079809511376

36. Wetter DW, Cofta-Gun L, Fouladi RT, Cinciprini PM, Sui D, Gritz ER. Late relapse/sustained abstinence among former smokers: a longitudinal study. Prev Med. 2004;39(6):1156-63. https://doi. org/10.1016/j.ypmed.2004.04.028

37. Gilpin EA, Pierce JP, Farkas AJ. Duration of smoking abstinence and success in quitting. J Natl Cancer Inst. 1997;89(8):572-6. https://doi. org/10.1093/jnci/89.8.572

38. Fernández E, Schiaffino A, Borrell C, Benach J, Ariza C, Ramon JM, et al. Social class, education, and smoking cessation: Long-term followup of patients treated at a smoking cessation unit. Nicotine Tob Res. 2006;8(1):29-36. https://doi.org/10.1080/14622200500264432 